\title{
Evaluation of sensitivity of two serological tests for diagnosing pneumonia caused by Legionella pneumophila serogroup 1
}

\author{
T G HARRISON,** E DOURNON, $\dagger$ A G TAYLOR* \\ From the *Division of Microbiological Reagents and Quality Control, Central Public Health Laboratory, \\ London, and the †Laboratoire Central De L'Hôpital Claude-Bernard, Paris, France
}

SUMMARY The sensitivity of an indirect immunofluorescence antibody test (IFAT) and a rapid microagglutination test (RMAT) for the diagnosis of Legionnaires' disease caused by Legionella pneumophila serogroup 1 was evaluated using serum specimens from 119 patients with bacteriologically confirmed infections. The sensitivity of both assays was found to be about $80 \%$. In addition, antibody titres suggestive of $L$ pneumophila infection were found in $40 \%$ of patients in the first week after admission to hospital. These data show that both assays can be used with confidence in the early diagnosis of Legionnaires' disease.

We have previously described two assays for the serodiagnosis of Legionnaires' disease caused by Legionella pneumophila serogroup 1 . These are an indirect immunofluorescence antibody test (IFAT) using formolised yolk sac antigen prepared from the Pontiac strain of $L$ pneumophila ${ }^{1}$ and a semiautomatable rapid microagglutination test (RMAT) using a formalin killed suspension of bacteria grown on solid media. ${ }^{2}$ These assays are used routinely within the Public Health Laboratory Service and other clinical diagnostic laboratories in the United Kingdom, as well as in some similar laboratories in other European countries. Results have been published which show that these tests have good specificity and are reproducible, ${ }^{3}$ but to date the sensitivity of the assays has only been determined using sera from a small number of patients with bacteriologically confirmed Legionnaires' disease.

This study reports the results obtained by examining sera from a large series of patients in whom Legionnaires' disease had been bacteriologically confirmed. In addition to providing an accurate assessment of the sensitivity of each assay, it was intended that such a study would also show features of Legionnaires' disease which lead to problems in its serodiagnosis.

Accepted for publication 29 July 1986

\section{Material and methods}

PATIENTS

Patients were included in the series provided that they had a pneumonic illness clinically compatible with a diagnosis of Legionnaires' disease and that such a diagnosis was confirmed either by culture of $L$ pneumophila serogroup 1 from clinical specimens or by showing the organism by immunofluorescence antibody staining, and that at least one serum specimen was available for the estimation of antibody titres.

Specimens were obtained from 119 patients who fulfilled these criteria- 92 from the Hôpital ClaudeBernard and 27 from the Central Public Health Laboratory (CPHL). The diagnosis had been established by culture in 103 cases, by fluorescence antibody demonstration of the organism in lower respiratory tract specimens in 15 cases, and by fluorescence antibody demonstration of the organism in sputum in one case (table 1). Where possible, the following informa-

Table 1 Evidence of infection in 119 patients with Legionnaires' disease

\begin{tabular}{lr}
\hline $\begin{array}{l}\text { Isolation of Legionella pneumophila serogroup } 1 \text { from: } \\
\text { Respiratory tract specimen }\end{array}$ & 100 \\
Necropsy lung tissue & 3 \\
Fluorescence antibody demonstration of organism in either: \\
$\quad \begin{array}{l}\text { Lung biopsy tissue, bronchoalveolar lavage } \\
\text { specimens, transtracheal aspirates, or formalin } \\
\text { fixed necropsy lung tissue }\end{array}$ \\
$\begin{array}{l}\text { Fluorescence antibody demonstration of organism } \\
\text { in sputum }\end{array}$ \\
\hline
\end{tabular}


tion was obtained for each patient:

1 The date of onset of symptoms (this was usually provided by the patients and is therefore somewhat subjective).

2 The date of admission to hospital (in the case of a patient who acquired Legionnaires' disease nosocomially the date of onset was used in place of the date of admission). A case was considered to be nosocomial if the onset of symptoms occurred 12 or more days after admission to hospital for an unrelated reason.

3 The dates on which blood specimens were taken.

4 The outcome of the illness (fatal or not).

5 Whether the patient was immunocompromised or not. The definition of an immunocompromised patient (used in this study) was as follows: a patient with generalised malignant disease or acquired immune deficiency syndrome (AIDS), or with a clearly shown primary immune defect, or a patient who was undergoing treatment with immunosuppressive drugs with one of the following regimens: steroids $\geqslant 3 \mathrm{mg} / \mathrm{kg} /$ day for 15 days or more or, $\geqslant 2 \mathrm{mg} / \mathrm{kg} / \mathrm{day}$ for 30 days or more; cyclosporin $\mathrm{A}$ (conventional regimen); cyclophosphamide (conventional regimen); azathioprine (conventional regimen); combined chemotheraphy for cancer, leukaemia, or lymphoma.

\section{SEROLOGY}

The IFAT and RMAT were performed as previously described, ${ }^{12}$ with the exception that the bacteria used for preparation of the RMAT antigen were grown on buffered charcoal yeast extract agar. ${ }^{4}$ Patients' serum specimens were examined by IFAT in either the Hôpital Claude-Bernard, or the CPHL. A selection of sera were examined in both centres to ensure that the results obtained were equivalent. The RMAT was performed only at CPHL.

Interpretation of serological results On the basis of serological results patients were considered to be:

(i) Serologically negative for Legionnaires' disease (if the antibody titres-of all available specimens were $<16$ in the IFAT and $<8$ in the RMAT).

(ii) Serologically diagnostic for Legionnaires' disease (if the criteria used previously to establish the diagnosis of Legionnaires' disease were met $^{12}$ - that is, for the IFAT, a four-fold or greater rise in titre to $\geqslant 64$ between paired sera, or a single or standing titre of $\geqslant 128$; for the RMAT, a four-fold rise in titre to $\geqslant 16$ between paired sera or a single or standing titre $\geqslant 32$ ).

(iii) Serologically positive (but not diagnostic) for Legionnaires' disease (if any specimens gave a titre of $\geqslant 16$ in the IFAT, a titre of $\geqslant 8$ in the RMAT, but the diagnostic criteria in (ii) were not met).

\section{Results}

EPIDEMIOLOGICAL FEATURES OF THE PATIENT POPULATION

Of the 119 patients, $89(74.8 \%)$ were men and 30 $(25.2 \%)$ were women, giving a male:female ratio of $3: 1$. The mean age was 52.7 years (range $2-87$ years, known for 109 patients), 53.5 years for men (range 18-87 years, known for 83 of 89 patients), and $50 \cdot 2$ years for women (range 2-87 years, known for 26 of 30 patients).

In this series 54 of $107(50.5 \%)$ patients were classified as immunocompromised and 53 of 107 $(49.5 \%)$ were apparently not immunocompromised (table 2). The 12 remaining patients could not be classified.

Of the 119 cases, 34 were nosocomial and 75 were community acquired (10 cases could not be classified). Thirty of the 34 nosocomial cases were immunocompromised. In one case data were unavailable. The fatality rate in this series was very high as $\mathbf{4 6}$ of 109 $(42.2 \%)$ patients died (10 patients not known). It was noted that nine of $28(32.1 \%)$ women had a fatal outcome as opposed to 37 of $81(46 \cdot 2 \%)$ men $\left(\chi^{2}=1.56\right.$, $\mathrm{p}>0 \cdot 1$, not significant).

\section{SENSITIVITY OF IFAT AND RMAT}

Three hundred and ninety seven serum specimens were available for examination by IFAT from the 119 patients. Only one specimen was available from 22 patients. From the results obtained (table 3) it can be seen that sensitivity of the IFAT with respect to a diagnostic result was $79 \cdot 0 \%$. In addition, a further

Table 2 Underlying illness of 54 immunocompromised patients with Legionnaires' disease

\begin{tabular}{lc}
\hline $\begin{array}{l}\text { Malignancies: } \\
\text { Leukaemia }\end{array}$ & $14(12)$ \\
Lymphoma & $6(3 / 5)^{*}$ \\
Other malignancies & $7(3 / 6)^{*}$ \\
& \\
Non-malignant illnesses treated with steroids in combination with \\
cyclophosphamide, cyclosporin A, or azathioprine: \\
Renal or heart or liver transplantations & 11 \\
Systemic lupus erythematosus & 1 \\
Rheumatoid arthritis & 1 \\
Polyarteritis nodosa & 2 \\
Goodpasture's syndrome & 1 \\
& \\
Non-malignant illnesses treated with steroids alone: & 4 \\
Chronic bronchitis or asthma & 2 \\
Systemic lupus erythematosus & 1 \\
Rheumatoid arthritis & 1 \\
Brain oedema & 1 \\
Not stated & \\
Others & 2 \\
AIDS & \\
\hline
\end{tabular}

Figures in parentheses indicate No of patients treated with steroids or cytotoxic drugs.

*Data not supplied for one patient. 
Table 3 Sensitivity of IFAT

\begin{tabular}{|c|c|c|c|}
\hline Test result & No of patien & $s(\%)$ & \\
\hline $\begin{array}{l}\text { Four-fold rise } \\
\text { Single specimen } \\
\text { Standing titre }\end{array}$ & $\left.\begin{array}{l}71(59 \cdot 7) \\
13(10.9) \\
10(8.4)\end{array}\right\}$ & Diagnostic & $94(79 \cdot 0)$ \\
\hline $\begin{array}{l}\text { A two or four-fold } \\
\text { rise to }<32 \\
\text { Single specimen } \\
\text { Standing titre }\end{array}$ & $\left.\begin{array}{l}5(4 \cdot 2) \\
5(4 \cdot 2) \\
2(1 \cdot 7)\end{array}\right\}$ & $\begin{array}{l}\text { Positive but not } \\
\text { diagnostic } \\
\text { Negative }\end{array}$ & $\begin{array}{l}12(10 \cdot 1) \\
13(10.9)\end{array}$ \\
\hline $\begin{array}{l}\text { Total } \\
\text { Positive }\end{array}$ & & & $\begin{array}{l}119(100) \\
106(89 \cdot 1)\end{array}$ \\
\hline
\end{tabular}

$10 \cdot 1 \%$ of specimens gave positive but not diagnostic results. The remaining $10.9 \%$ of specimens gave negative results.

Specimens were not available from four of 119 patients for examination in the RMAT. Thus 376 serum specimens from 115 patients were tested. The sensitivity of the RMAT, with respect to a diagnostic result, was $81.7 \%$; a further $7.0 \%$ of the results were positive but not diagnostic; and $11 \cdot 3 \%$ were negative (table 4).

If the IFAT and RMAT results are considered together diagnostic titres were obtained in $86.9 \%$; positive but not diagnostic titres in $4.4 \%$; and negative titres in $8.7 \%$ of the 115 cases (table 5).

Specimens from 16 of the 119 patients gave negative results in one or both assays. Three were positive (two diagnostic) by IFAT and negative by RMAT, while one was diagnostic by RMAT and negative by IFAT. Ten cases were negative in both assays and two were IFAT negative and not tested in the RMAT. Thus of the 115 patients tested in both assays, the RMAT and IFAT showed concordance in 111 $(96.5 \%)$ cases.

\section{TIMING OF THE ANTIBODY RESPONSE}

The dates of both onset of illness and collection of the first serum specimen were known for 100 patients, and the average interval of time between these was $7 \cdot 3$ days (range one to 28). Similarly, the average time between admission and collection of the first serum

Table 4 Sensitivity of RMAT

\begin{tabular}{|c|c|c|c|}
\hline Test result & No of patien & $s(\%)$ & \\
\hline $\begin{array}{l}\text { Four-fold rise } \\
\text { Single specimen } \\
\text { Standing titre }\end{array}$ & $\left.\begin{array}{r}72(62.6) \\
13(11.3) \\
9(7.8)\end{array}\right\}$ & Diagnostic & $94(81 \cdot 7)$ \\
\hline \multirow[t]{2}{*}{$\begin{array}{l}\text { Two-fold rise } \\
\text { Single specimen } \\
\text { Standing titre }\end{array}$} & \multirow{2}{*}{$\left.\begin{array}{l}2(1 \cdot 8) \\
3(2 \cdot 6) \\
3(2 \cdot 6)\end{array}\right\}$} & $\begin{array}{l}\text { Positive but not } \\
\text { diagnostic }\end{array}$ & $8(7 \cdot 0)$ \\
\hline & & Negative & $13(11 \cdot 3)$ \\
\hline $\begin{array}{l}\text { Total } \\
\text { Positive }\end{array}$ & & & $\begin{array}{l}115(100) \\
102(88 \cdot 7)\end{array}$ \\
\hline
\end{tabular}

Table 5 Sensitivity obtained using combination of IFAT and $R M A T$

\begin{tabular}{|c|c|c|c|}
\hline Test result & No of patien & $s(\%)$ & \\
\hline $\begin{array}{l}\text { Four-fold rise } \\
\text { Single specimen } \\
\text { Standing titre }\end{array}$ & $\left.\begin{array}{c}82(71 \cdot 3) \\
15(13 \cdot 0) \\
3(2 \cdot 6)\end{array}\right\}$ & Diagnostic & $100(86.9)$ \\
\hline $\begin{array}{l}\text { Two-fold rise } \\
\text { Single specimen } \\
\text { Standing titre }\end{array}$ & $\left.\begin{array}{l}1(0.8) \\
2(1.8) \\
2(1.8)\end{array}\right\}$ & $\begin{array}{l}\text { Positive but not } \\
\text { diagnostic } \\
\text { Negative }\end{array}$ & $\begin{array}{c}5(4 \cdot 4) \\
10(8 \cdot 7)\end{array}$ \\
\hline $\begin{array}{l}\text { Total } \\
\text { Positive }\end{array}$ & & & $\begin{array}{l}115(100) \\
105(91 \cdot 3)\end{array}$ \\
\hline
\end{tabular}

specimen was four and a half days (range 0-25, 101 known). Seventy seven of these specimens were taken in the first week zero to six days after admission and $31(40 \%)$ of these were positive in the IFAT, including nine of the 29 taken within 48 hours of admission (zero to one day). Sixty nine specimens taken in the first week were also examined in the RMAT and 31 $(45 \%)$ were positive, including nine of the 27 taken within 48 hours. Although most of these early positive results fell into the category of "positive but not diagnostic," a significant number were diagnostic$16 \%$ and $23 \%$ for the IFAT and RMAT, respectively.

FACTORS AFFECTING THE ANTIBODY RESPONSE

The data were analysed to see if any epidemiological features correlated with a particular result being obtained in the serological assays (for example, were serum specimens from older patients more likely to be negative than those from younger patients?).

Patients were banded by age and the proportions of positive and negative results in each category compared. No significant differences were found. Similarly, analyses according to the sex of patient and whether they were immunocompromised or not showed no significant differences.

The outcome of illness was known for 109 of the 119 patients. Of the 46 patients who died, negative IFAT results were obtained in 10 instances, while only three negative results were obtained with specimens from 63 patients who survived. This is a significant difference $\left(\chi^{2}\right.$ Yate's correction $=6 \cdot 15$, $\mathrm{p}<0.05)$.

A possible explanation for the difference in outcome might be that the only specimens available from the patients who died were collected soon after onset of Legionnaires' disease, before antibody was present at detectable titres. To determine whether this was the case the following analyses were performed:

1 The timing of death in relation to onset of illness was compared for seronegative and seropositive patients. The mean number of days between onset and death was 12.7 days (range four to $30, n=8$ ) for 
IFAT seronegative patients and 15.5 days (range five to $31, \mathrm{n}=19$ ) for IFAT seropositive patients.

2 The number of days between onset and the collection of last available specimen from IFAT seronegative patients who died was compared with the time from onset to the collection of the first serum specimen to give a positive result from IFAT seropositive patients who died. The mean for seronegative patients was 10.2 days (range four to $20, n=9$ ) and was 11.5 days (range four to $35, \mathrm{n}=30$ ) for seropositive patients.

3 The number of days between onset and the last available serum specimen (taken within a month of onset) from seronegative patients (irrespective of the outcome of illness) was compared with the time from onset to the collection of the first serum specimen to give a positive IFAT result from seropositive patients (irrespective of the outcome of illness). The mean intervals were 9.6 days (range three to $20, \mathrm{n}=11$ ) and 12.0 days (range three to $35, \mathrm{n}=89$ ), respectively.

None of the differences observed between the groups approached significance, but as some of the groups contained only a few patients it is hard to draw any conclusions from these results.

\section{Discussion}

If a serological assay is to provide results helpful in the diagnosis of a patients's illness it must be rigourously evaluated. Variables such as the test sensitivity and specificity must be determined and from these the predictive values calculated. ${ }^{5}$

The most important test variable in the case of an illness of low prevalence, such as Legionnaires' disease, is the specificity. This has been determined previously for both the IFAT and the RMAT, as used in this study, with regard to infections caused by $L$ pneumophila serogroup $1 .{ }^{3}$ It was shown that the specificity was excellent for both assays being $100 \%$ for a diagnostic result in the IFAT and $99.6 \%$ for the RMAT. In addition, it was shown that both the IFAT and RMAT were highly specific (about $97 \%$ ) even with respect to positive, but not necessarily diagnostic, results.

The high specificity of these two assays indicates that considerable confidence can be placed in the validity of the diagnosis where specimens from a patient give serodiagnostic results. Unless the sensitivity has been determined, however, the percentage of patients who have Legionnaires' disease but fail to give serodiagnostic results will be unknown.

Although many serological assays have been described for the diagnosis of Legionnaires' disease, few have been adequately evaluated. Where attempts have been made to determine the sensitivity, these have often been of limited value as the serum specimens examined were from patients whose illness had been diagnosed using another poorly evaluated serological test. ${ }^{6}$

Wilkinson et $^{7}{ }^{7}$ evaluated an IFAT that uses a different type of antigen and different diagnostic criteria from those used in our IFAT: sera from patients from six well documented outbreaks of legionellosis were examined. This use of epidemic sera provided an alternative source of evidence for the patients' illness and this epidemiological approach was the best method available at the time. Inevitably the estimate of sensitivity was biased as the definitions of a case of Legionnaires' disease used in such epidemiological studies often included the consideration of serological results.

In the study presented here the estimate of the sensitivity of the IFAT and RMAT were determined using sera from 119 patients in whom Legionnaires' disease was diagnosed either by culture or demonstration of the organism in patients' specimens, or both of these methods. The results show that the IFAT has a sensitivity of $79.0 \%$ and the RMAT $81.7 \%$ with respect to a diagnostic result. From these results the predictive value of a diagnostic result in the RMAT is calculated to be between 67 and $91 \%$, assuming the prevalence of Legionnaires' disease caused by $L$ pneumophila serogroup 1 is $1-5 \%$ of patients with pneumonia. As the specificity of the IFAT is calculated as $100 \%$ the predictive value of a positive result is also $100 \%$, irrespective of the sensitivity. ${ }^{5}$

In the case of both assays, although specimens from about $20 \%$ of the patients failed to give diagnostic results, positive titres were shown in about half $(10 \%$ of the total) of these. While these results are not conclusive, they can be good indicators of a case of Legionnaires' disease (table 5). Where a combination of both the IFAT and RMAT were used, the sensitivity of a diagnostic result rose from $79 \%$ and $81.7 \%$, respectively, to $86.9 \%$. This increase is accounted for largely by a decrease in the percentage of positive (but not diagnostic) results. The reliability of a diagnosis based on such positive results is affected by the prevalence of Legionnaires' disease in the population being examined. If the prevalence of Legionnaires' disease is $1-5 \%$ the predictive value of any positive IFAT or RMAT result is $23-60 \%$.

The concordance seen between the IFAT and RMAT was very high (96.5\%), but discrepant results were seen in four instances. In one of these (case 1, table 6) one specimen was taken five days after onset of symptoms. This specimen had an IFAT titre of 128 but was negative in the RMAT. Subsequent analysis showed the specific antibody to be only of the IgG immunogobulin class. This probably accounts for the discrepant results--being an agglutination assay, the 
Table 6 Summary of patients whose sera gave negative results in either IFAT or RMAT

\begin{tabular}{|c|c|c|c|c|}
\hline Case No & Fatal* & $I F A T$ & $R M A T$ & Days specimen takent \\
\hline $\begin{array}{r}1 \\
2 \\
3 \\
4 \\
5 \\
6 \\
7 \\
8 \\
9 \\
10 \\
11 \\
12 \\
13 \\
14 \\
15 \\
16\end{array}$ & $\begin{array}{l}\text { Yes (not known) } \\
\text { No } \\
\text { Yes (23) } \\
\text { No } \\
\text { Yes (4) } \\
\text { Yes (15) } \\
\text { Yes (6) } \\
\text { Yes (12) } \\
\text { Yes (11) } \\
\text { Yes (30) } \\
\text { Yes (11) } \\
\text { No } \\
\text { Yes (9) } \\
\text { Not known } \\
\text { Yes (not known) } \\
\text { Yes (22) }\end{array}$ & $\begin{array}{l}\text { Diagnostic } \\
\text { Diagnostic } \\
\text { Positive } \\
\text { Negative } \\
\text { Negative } \\
\text { Negative } \\
\text { Negative } \\
\text { Negative } \\
\text { Negative } \\
\text { Negative } \\
\text { Negative } \\
\text { Negative } \\
\text { Negative } \\
\text { Negative } \\
\text { Negative } \\
\text { Negative }\end{array}$ & $\begin{array}{l}\text { Negative } \\
\text { Negative } \\
\text { Negative } \\
\text { Diagnostic } \\
\text { Negative } \\
\text { Negative } \\
\text { Negative } \\
\text { Negative } \\
\text { Negative } \\
\text { Not tested } \\
\text { Negative } \\
\text { Negative } \\
\text { Negative } \\
\text { Not tested } \\
\text { Negative } \\
\text { Negative }\end{array}$ & $\begin{array}{l}5 \text { (IgG only) } \\
1,2,7,31 \\
12,15 \\
3,10,218 \\
3 \\
3,8 \\
4 \\
5 \\
7 \\
8,9,10,13,16 \\
10 \\
3,37 \\
\leqslant 9 \\
\text { Not known } \\
11,20 \\
10,19\end{array}$ \\
\hline
\end{tabular}

*Figures in parentheses indicate the number of days after the onset of symptoms when the patient died. †Days after onset.

RMAT is inefficient at detecting this class of antibody. $^{8}$

Of particular interest are the specimens from case 4 (table 6). A diagnostic rise between the first specimen (three days after onset) and the second specimen (10 days) was shown by RMAT. These sera were negative by IFAT, and a third specimen (218 days) was negative in both assays. It is possible that had an appropriately timed third specimen been available a seroconversion would have been shown by IFAT, but this result does indicate that a RMAT diagnostic IFAT negative result is not necessarily a false positive result, as had been assumed previously. ${ }^{2}$

Specimens from 10 patients were negative in both assays. Attempts were made to determine any features which distinguished this group from the other patients. The seronegative patients did not differ significantly in age, sex, and in whether they were immunocompromised or not from the remaining patients. It was found, however, that patients who died were more likely to have been seronegative than patients who survived. One possible explanation for this observation could be that appropriately timed serum specimens were not available from some of the patients with a fatal outcome. Although analysis of the data presented here does not support this explanation, it should not be discounted as the numbers of patients in the seronegative group were small and hence only major differences in the timing of serum specimens would have been detected.

It can be seen from the epidemiological data that the series of patients selected was a biased sample from the general population of patients with Legionnaires' disease. Although the age range and male: female ratios were typical, ${ }^{9}$ the mortality was considerably higher than usual. ${ }^{9}$ Over $50 \%$ of the patients were also immunocompromised. This, together with the fact that $67 \%$ (of those reported) required mechanical ventilation, suggests that the patients in this population were more severely ill than is typical in Legionnaires' disease. This is not surprising as it is probable that a severely ill patient will be investigated with greater rapidity and more intensively than those with milder disease, and hence $L$ pneumophila will be isolated more often.

As discussed above, patients who died were more often seronegative than those who survived. As the percentage mortality in this series of patients exceeded that which would usually be expected, it may be that the percentage of seronegative patients was also excessive. Thus the sensitivities calculated here may be underestimates of the true values.

This study was not undertaken to investigate the timing of the antibody response in legionella infections, but the data presented illustrate an important point. In both assays about a third of the specimens taken from patients within 48 hours of admission to hospital were positive, and within a week of admission this figure had risen to over $40 \%$. This clearly shows that when appropriate specimens are taken an early indication of a legionella infection can be obtained.

Conflicting results have been reported on the value of serology, especially in patient management in cases of Legionnaires' disease. There are two main explanations for this. Firstly, different techniques and antigen preparations have been used. Secondly, serological criteria established for the diagnosis of Legionnaires' disease caused by $L$ pneumophila serogroup 1 have been extended to the many other serogroups and species now known, without any real assessment of the specificity or sensitivity of the serological tests using these different antigens.

We have previously shown that the IFAT using for- 
molised yolk sac antigen and the RMAT are highly specific. We have now shown that these tests have a similar sensitivity of about $80 \%$, even in very severe cases and in immunocompromised patients. Overall, the sensitivity and specificity of these assays are such that they can be used with confidence in the early diagnosis of Legionnaires' disease. In our hands about $40 \%$ of patients with Legionnaires' disease confirmed by culture caused by $L$ pneumophila serogroup 1 do have antibodies likely to indicate such an infection during the first week after admission to hospital.

\section{References}

1 Harrison TG, Taylor AG. Diagnosis of Legionella pneumophila infections by means of formolised yolk sac antigens. $J$ Clin Pathol 1982;35:211-4.

2 Harrison TG, Taylor AG. A rapid microagglutination test for the diagnosis of Legionella pneumophila (serogroup 1) infection. $J$ Clin Pathol 1982;35:1028-31.

3 Taylor AG, Harrison TG. Serological tests for Legionella pneu- mophila serogroup 1 infections. Zentralbl Bakteriol Hyg (Orig A) 1983;255:20-6.

4 Pasculle AW, Feeley JC, Gibson RJ, et al. Pittsburgh pneumonia agent: direct isolation from human lung tissue. $J$ Infect Dis 1980;141:727-32.

5 Vecchio TJ. Predictive value of a single diagnostic test in unselected populations. New Engl J Med 1966;274:1171-3.

6 Stanek G, Hirschl A, Lessky E, Wewalka F, Ruckdeschel G, Wewalka G. Indirect immunofluorescence assay (IFA), microagglutination test (MA) and enzyme-linked-immunosorbent assay (ELISA) in diagnosis of Legionellosis. Zentralbl Bakteriol Hyg (Orig A) 1983;255:108-14.

7 Wilkinson HW, Cruce DD, Broome CV. Validation of Legionella pneumophila indirect immunofluorescence assay with epidemic sera. J Clin Microbiol 1981;13:139-46.

8 Pike RM. Antibody heterogeneity and serological reactions. Bacteriological Reviews 1967;31:157-74.

9 Bartlett C, Miller A. Legionnaires' disease. Medicine International 1981;1:183-5.

Requests for reprints to: Dr TG Harrison, Division of Microbiological Reagents and Quality Control, Central Public Health Laboratory, 61 Colindale Avenue, London NW9 5HT, England. 